\title{
Cardiac Troponin I: Ultrasensitive Detection Using Faradaic Electrochemical Impedance
}

\author{
Elaine Spain, ${ }^{* \dagger}{ }^{\dagger}$ Serena Carrara, ${ }^{\ddagger}$ Kellie Adamson, ${ }^{\dagger, \S}$ Hui Ma, ${ }^{*}$ Richard O’Kennedy, ${ }^{\|, \perp}$ \\ Luisa De Cola, ${ }^{\ddagger 0}$ and Robert J. Forster* ${ }^{* \dagger}$
}

\author{
${ }^{\dagger}$ National Centre for Sensor Research and "School of Biotechnology, Dublin City University, Collins Avenue, D09 Y5N0, 9 Dublin, \\ Ireland \\ "Universitè de Strasbourg, CNRS, ISIS \& icFRC, 8 Allée Gaspard Monge, 67083 Strasbourg, France \\ ${ }^{\S}$ School of Chemistry, National University of Ireland Galway, H91 TK33 Galway, Ireland \\ ${ }^{\perp}$ Qatar Biomedical Research Institute, Hamad Bin Khalifa University, Doha, Qatar
}

Supporting Information

\begin{abstract}
An electrochemical biosensor for the detection of cardiac troponin I, cTnI, an important cardiac biomarker, is described. A combination of a novel monoclonal antibody, mAb20B3, and a novel Ir(III)-based metal complex was used for detection using faradaic electrochemical impedance spectroscopy. A limit of detection of $10 \mathrm{ag} / \mathrm{mL}$ was achieved, which is significantly lower than established assays. The ability to detect these ultralow concentrations enables rapid and early stage detection of cardiac events and opens up the possibility of developing a pointof-care device.
\end{abstract}

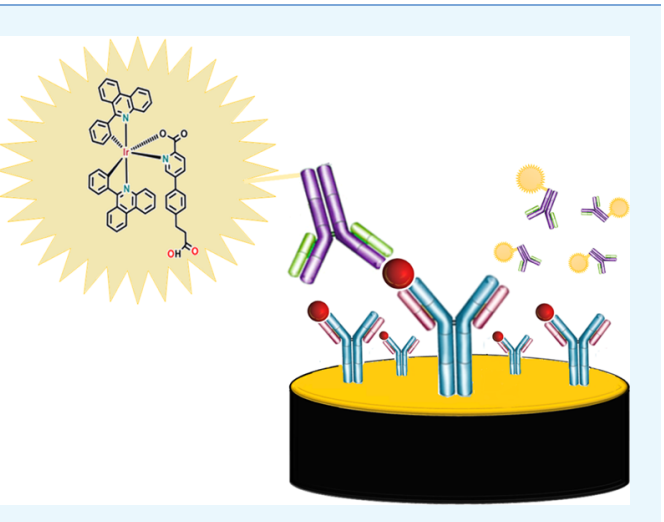

\section{INTRODUCTION}

Cardiovascular disease (CVD) is one of the most prevalent causes of human death in both developing and developed countries. ${ }^{1}$ The World Health Organization estimates that on an average, $30 \%$ of all global deaths are associated with CVD, and it may be one of the leading causes of death in developing countries. ${ }^{2,3}$ Acute myocardial infarction (AMI) is the leading type of CVD and occurs when part of the heart muscle is damaged following blockage of a coronary artery. AMI management and its rapid diagnosis, for example, through a molecular biomarker, are required ${ }^{4}$ is extremely time-sensitive. Several biomarkers have been explored for the detection of AMI, for example, creatine kinase MB (CK-MB), myoglobin, and cardiac troponin ( $\mathrm{cTn}) .^{5}$ The latter is recommended as a biomarker of choice for acute coronary syndrome. cTn exists as a complex between three single-chain polypeptides: troponin $T$ $(c \operatorname{Tn} T)$ binds the other troponin components to tropomyosin, troponin I ( $c T n I)$ inhibits ATP activity when bound to actin, and troponin $C(c \operatorname{Tn} C)$ contains binding sites for calcium. In general, upon AMI, the troponin complex becomes fragmented, and the individual protein components are then released into the bloodstream. Among the three types of troponins, cTnI (molecular weight $23876 \mathrm{Da}$ ) is preferred for detection because of its superior cardiac specificity and selectivity. ${ }^{6}$ The concentration of $\mathrm{cTnI}$ increases within 2-6 $\mathrm{h}$ upon the onset of AMI and reaches a maximum concentration of the order of $50 \mathrm{ng} / \mathrm{mL}$ during the next $24 \mathrm{~h}^{7}$
Accurate and rapid determination of cTnI is very important for early diagnosis and appropriate treatment of AMI. Typically, within 2-12 h upon the onset of AMI, cTnI levels rise in the serum and remain elevated for 5-10 days. ${ }^{8}$ Because of the crucial need for early diagnosis, cTnI testing should be performed within 3-4 h after the suspected onset of AMI. To date, several techniques have been reported for cTnI detection including enzyme-linked immunosorbent assay, ${ }^{9,10}$ use of optomagnetism, ${ }^{11}$ field-effect transistor-based analysis, ${ }^{12}$ fluorescence immunoassay, ${ }^{13}$ and electrochemiluminescence (ECL)-based biosensors. ${ }^{14-17}$ The development of electrochemical immunosensors based on electrochemical impedance spectroscopy $(E I S)^{18-21}$ can provide direct sensitive and selective detection and is suitable for developing a point-ofcare device. ${ }^{22}$ Limits of detection (LOD) in the nanometerpicometer range under controlled laboratory conditions have been reported for impedance-based biosensors. ${ }^{23-28}$ In particular, recent studies have reported on significant LOD detection of cTnI using EIS $^{3}$ (Table 1) and their promising application as early detection and management of CVD.

In this contribution, a novel monoclonal antibody $\left({ }^{*} \mathrm{mAb}\right)$, mAb20B3, specific to epitope 24-39 region of troponin I (cTnI) was investigated as either the primary (capture) or,

Received: July 24, 2018

Accepted: November 27, 2018

Published: December 12, 2018 
Table 1. Recent Studies on cTnI Biomarker Detection Impedance Methods

\begin{tabular}{lccc}
\multicolumn{1}{c}{ transducer } & linearity range $\left(\mathrm{mL}^{-1}\right)$ & LOD/LOQ $\left(\mathrm{mL}^{-1}\right)$ & $\mathrm{refs}$ \\
$\mathrm{Au} / \mathrm{MHA} / \mathrm{TMB} / \mathrm{Den} /$ anti-cTnI/Au electrode & $0.001-1 \mathrm{ng}$ & $0.0002 \mathrm{ng}$ & 35 \\
anti-cTnI/CNF nanoelectrode & $0-10 \mathrm{ng}$ & $0.2 \mathrm{ng}$ & 36 \\
$\mathrm{Mn}_{3} \mathrm{O}_{4}-\mathrm{RGO} /$ microfluidic electrode & $0.008-20 \mathrm{ng}$ & $8.0 \mathrm{pg}$ & 37 \\
anti-cTnI/Ag(MPA)/APTES/ITO & $20 \mathrm{ng}$ to $1 \mu \mathrm{g}$ & $5.5 \mathrm{ng}$ & 38
\end{tabular}

when labeled with a novel iridium metal complex, as secondary (detection) antibody in sandwich assays on a gold disk electrode. Cyclometalated iridium(III) complexes, because of their easily modifiable optical, photophysical, and electrochemical properties, are increasingly being applied in biological applications. $^{29-33}$ Compared to traditionally studied complexes such as $\mathrm{Ru}(\mathrm{bpy})_{3}{ }_{3}^{2+}$, cyclometalated $\mathrm{Ir}(\mathrm{III})$ complexes have higher photoluminescence efficiency and easy tunability of the emission wavelength, which is extremely useful for multiplexed detection of several biomarkers without separation. ${ }^{34}$ Additionally, iridium(III) complexes have presented the ability to hinder electron transfer between the electrode surface and the electrolyte because of the hydrophobicity and the large molecular structure of the complex. ${ }^{33}$ As a result of these multiple properties, Ir(III) complexes have recently been successfully applied as electrochemical enhancement probes for biological sensor. ${ }^{32,33}$

Moreover, this sensor, compared to those reported previously for cardiac biomarker detection, ${ }^{14-17}$ replaces the conventional $\mathrm{Ru}(\mathrm{bpy})_{3}{ }^{2+}$ by using a brighter $\mathrm{Ir}$ (II) metal complex, presents higher sensitivity, and permits fast, reliable, and inexpensive detection of lower quantities of antigen, which is supported by confocal microscopy. In this work, the investigation of $\operatorname{Ir}(\mathrm{III})$-labeled antibodies and their ability to enhance the detection of cTn by EIS and confocal microscopy, has, to our knowledge, not yet been reported.

Scheme 1 illustrates the detection strategy. The electrode, modified with the capture antibody, was incubated with

Scheme 1. Troponin I (cTnI)-Specific Immunosensor Based on Capturing Novel Ir(III)-Based Metal Complexes in a Sandwich Assay

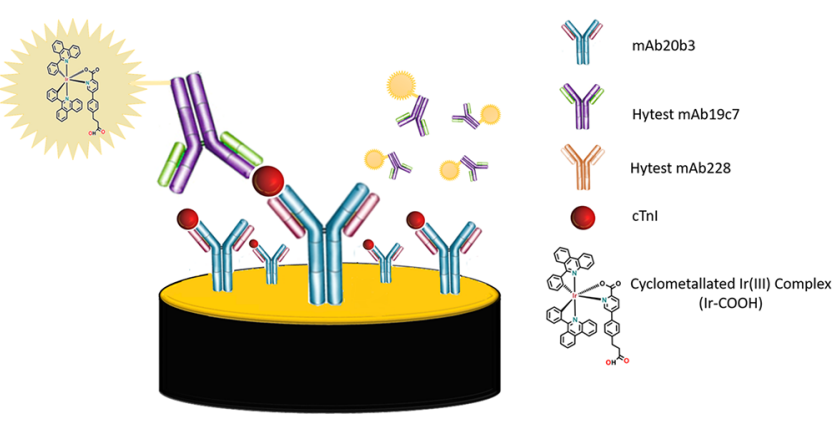

various concentrations of troponin $\mathrm{I}$ in the range of $1 \mathrm{ag} / \mathrm{mL}$ to $1 \mathrm{ng} / \mathrm{mL}$. A secondary antibody specific to a different epitope region (epitope region 41-49) of cTnI, labeled with a redoxactive cyclometalated $\operatorname{Ir}(\mathrm{III})$ complex, was then attached and the faradic impedance was measured. Currently, LOD for cTnI assays are in the $80-100 \mathrm{fg} / \mathrm{mL}$ range using electrochemical methods, for example, ECL biosensors, ${ }^{10}$ which compare favorably with other analytical methods. ${ }^{6-9}$ The approach reported here is expected to have significant applications for the detection of low levels of $\mathrm{cTnI}(\mathrm{ag} / \mathrm{mL})$ as a promising, rapid, and precise alternative to current time-consuming, conventional methods. The superior analytical performance could allow cTnI to be rapidly detected in the early stage of AMI.

\section{RESULTS AND DISCUSSION}

Electrochemical Impedance Studies. EIS detection provides an extremely rapid, simple, and sensitive method for biological samples. Detecting cTnI before and after any AMI symptoms is a vital component of routine heart checkups. Therefore, there is a significant drive to develop an easy, highly accurate, and robust label-free EIS detection method for trace cTnI before and after AMI symptoms in addition to therapeutic monitoring of the disease. Normally, protein quantifications in a biofluid are detected in EIS measurements using a redox probe in solution whose heterogeneous electron-transfer rate constant $^{39,40}$ is dependent on antibody-antigen binding. External redox probes, for example, ferricyanide, used during the impedance measurements may change the biological system, leading to a decreased sensitivity. ${ }^{41}$ However, if the redox probe is attached to the detection probe surface (i.e., secondary antibody) instead of being a redox-active electrochemical probe in solution, the antibody-cTnI binding events can be detected in a dilute Dulbecco's phosphate-buffered solution (DPBS). Thus, a suitable nontoxic redox probe can potentially be covalently attached to the secondary antibody.

In this study, a dilute electrolyte, $0.001 \mathrm{M}$ DPBS, was utilized for EIS so that the double-layer thickness was comparable to the thickness of the antibody-target-secondary antibody/Ir-COOH layer, thus making the measurement sensitive to changes occurring within that film. ${ }^{20,41-43}$ Changes in the EIS spectra can be related to the change in resistance and capacitance of the interface, thus providing insights into the effects of both surface modification and analyte binding. ${ }^{44}$ In particular, this dilute concentration of electrolyte ensures that both cell resistance (intersection of the right-hand side of the Nyquist semicircle with the $x$-axis) and capacitances depend strongly on cTnI concentration (surface coverage).

Novel mAb20B3 as the Primary Capture Antibody. Step 1. Modification of gold surface was monitored using EIS (Supporting Information, Figure S4). The EIS data were analyzed by Nyquist plots. Nyquist plots show the frequency response of the electrode/electrolyte system and plot the imaginary component $\left(Z^{\prime \prime}\right)$ of the impedance against the real component $\left(Z^{\prime}\right)$. The interfacial resistance $\left(R_{\mathrm{ct}}\right)$ at the electrode surface is given by the semicircle diameter obtained in EIS. ${ }^{45}$ In the present study, non-faradaic electrochemical impedance study measurements were first carried out to characterize the formation of self-assembled monolayers (SAMs) of 16-mercaptohexadecanoic acid (16-MHDA) and attachment of the in-house mAb20B3 antibody (specific to troponin epitope region 24-39) onto a gold disk electrode. A clear semicircle was observed for the bare gold electrode, and the $R_{\mathrm{ct}}$ value was determined to be about $248 \pm 116 \Omega$ (Supporting Information, Figure S2) for 60 independent electrodes. The $R_{\mathrm{ct}}$ value increased to $2064 \pm 64 \Omega$ for the 
electrode modified with 16-MHDA. After the immobilization of mAb20B3 $(100 \mu \mathrm{g} / \mathrm{mL})$ on the Au/MHDA electrode, the average $R_{\mathrm{ct}}$ value of 30 electrodes further increased to $4019 \pm$ $89 \Omega$. The increased $R_{\mathrm{ct}}$ arises from hindered ion transport, indicating successful immobilization of the mAbs. ${ }^{19}$ The properties of a commercial $\mathrm{mAb}$ (Hytest mAb228) with a similar epitope (epitope region 26-35) were also measured. In comparison to the novel monoclonal $\mathrm{mAb}(4019 \pm 89 \Omega)$, the commercially available mAbs (Hytest 228) exhibited an average $(n=30) R_{\mathrm{ct}}$ value of $3151 \pm 569 \Omega$ (Supporting Information, Figure S5). This lower resistance suggests a more porous antibody layer.

Step 2: Impedance Characteristics of the cTnI Immunosensor. The change in interfacial resistance was monitored as the cTnI concentration varied systematically from $1 \mathrm{ng} / \mathrm{mL}$ to $1 \mathrm{ag} / \mathrm{mL}(n=3)$ (Supporting Information, Figure S6). EIS responses were recorded in the presence of $1 \mathrm{mM}$ DPBS using an amplitude of $25 \mathrm{mV}$ and the direct current (dc) potential set to the open-circuit potential (OCP). The frequency range was between 0.01 and $100000 \mathrm{~Hz}$. To ensure that the doublelayer thickness was comparable to the thickness of the antibody-target-secondary antibody layer, the electrolyte used was $1 \mathrm{mM}$. This ensured that the measurement was sensitive to changes occurring within that film itself. ${ }^{29}$

As demonstrated in Figures $1 \mathrm{~A}$ and S6 (Supporting Information), the interfacial resistance increased with increasing $\mathrm{cTnI}$ concentration, reflecting the binding of $\mathrm{cTnI}$ to the capture antibody (20B3) immobilized on the electrode. The best fit least-squares regression line is $y=925 \pm 94 x+20308$ \pm 1147 , indicating a high sensitivity and a low nonspecific background current and the relative standard deviation (RSD) was in between 3 and $5 \%(n=3)$ for all cTnI concentration levels. LOD defined as ( $3 \sigma /$ slope $)$ was determined to be 100 $\mathrm{ag} / \mathrm{mL}$. This range encompasses the clinically relevant range (usually up to $0.06-1.5 \mathrm{ng} / \mathrm{mL}$ in clinics). The sensitivity of the assay using the custom-synthesized mAb20B3 antibody, defined as the slope of calibration curve, is approximately 1.2 times higher than that found using a commercial antibody (Hytest 228, Figure 1A, $\square$ ) with a similar epitope. In addition, the commercial mAb-based immunosensor showed a higher LOD $(10 \mathrm{fg} / \mathrm{mL})$ than that obtained for the custom-generated $\mathrm{mAb}(100 \mathrm{ag} / \mathrm{mL})$. These results most likely reflect a higher association constant for the custom antibody with the cTnI target. The wide dynamic range, approximately 9 orders of magnitude, low LOD, and excellent sensitivity make the assay based on the custom antibody attractive for the development of a label-free, point-of-care cardiac diagnostic device. However, labeled antibody approaches can deliver even greater sensitivity without adding significant complexity to the measurement.

Step 3: Novel Ir(III) Secondary Antibody. After the capture of cTnI target, a secondary antibody (Hytest 19C7, specific to epitope region 41-49) labeled with the $\mathrm{Ir}-\mathrm{COOH}$ complex (Figure 1B) was bound to the primary antibody-target complex. The conformational changes associated with target binding a hydrophobic complex such as $\mathrm{Ir}-\mathrm{COOH}$ brings the redox reporter into close proximity to the electrode, yielding a change in the interfacial properties and therefore disturbing the electrochemical reaction and a more resistive behavior (higher impedance) can be expected. ${ }^{46,47}$ Subsequently, the interaction of iridium complex with increasing concentrations of cTnI leads to a remarkable increased electron-transfer resistance (Figure 1B, $\mathbf{\text { ) }}$. The high resistance of the electrode interface
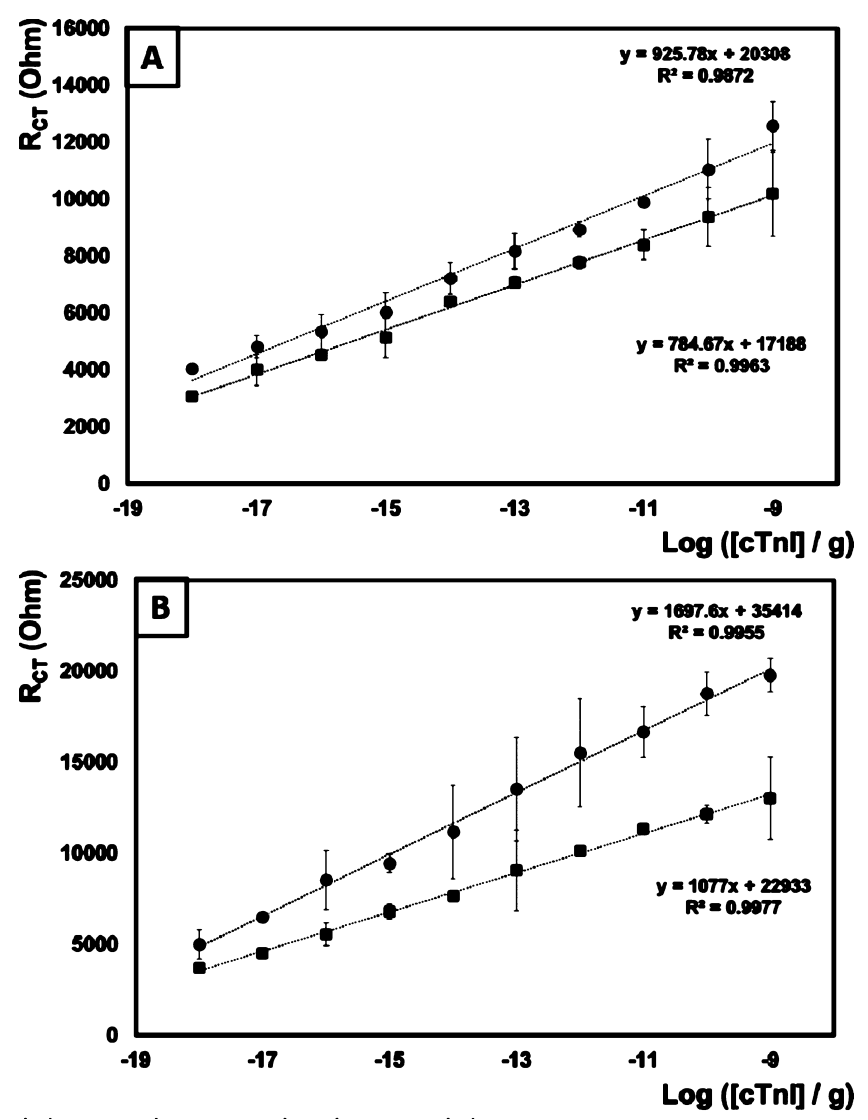

Figure 1. (A) Dependence of interfacial resistance $(n=3)$ on cTnI concentration where the primary antibodies are $m A b 20 B 3(\mathbf{O})$ and $m A b 228(\boldsymbol{\square})$, following exposure to increasing $\mathrm{cTnI}$ target $(1 \mathrm{ag} / \mathrm{mL}$ to $1 \mathrm{ng} / \mathrm{mL}$ ) and after immobilization of the Ir (III)-labeled commercial secondary antibody $m A b 19 C 7$ (B). In all cases, the supporting electrolyte is $1 \mathrm{mM}$ DPBS and EIS was recorded between 0.01 and $100000 \mathrm{~Hz}$ using an alternating current (ac) amplitude of 25 $\mathrm{mV}$ and the $\mathrm{dc}$ potential set to the OCP.

is induced by the adsorption of the iridium complex and the formation of a hydrophobic layer on the electrode surface. The target molecules show a good linear relationship between impedance and concentration of cTnI ranging from $1 \mathrm{ag} / \mathrm{mL}$ to $1 \mathrm{ng} / \mathrm{mL}$ with an $R^{2}$ value of 0.9955 . A 2 -fold increase in the calibration slope was observed after the conjugation of Ir$\mathrm{COOH}(1697.6 \Omega$, Figure $1 \mathrm{~B}, \mathbf{O})$ compared to the antibodycTnI-modified electrode (925.78 $\Omega$, Figure 1A, $\mathbf{O})$, indicating a high sensitivity of the assay. The observation that the corresponding was observed after the conjugation of Ir$\mathrm{COOH}(1697.6 \Omega$, Figure $1 \mathrm{~B}, \mathbf{O})$ compared to the antibodycTnI-modified electrode ( $925.78 \Omega$, Figure $1 \mathrm{~A}, \mathbf{O})$ indicating a high sensitivity of the assay. The corresponding resistance increases with $\mathrm{Ir}-\mathrm{COOH}$, demonstrating successful binding to the modified electrode. The observation that resistance increases linearly with $\log [\mathrm{cTnI}]$ rather than $[\mathrm{cTnI}]$ suggests that the current response is influenced by the successful binding of $\mathrm{Ir}-\mathrm{COOH}$ to the modified electrode as well as the cTnI concentration. To directly confirm that the Ir(III)labeled secondary antibody is indeed bound to cTnI, luminescence microscopy was carried out (Figure 2). Similar to the results of electrochemistry studies, the fluorescence on the gold surface only changes when the electrode is incubated with $\mathrm{Ir}-\mathrm{COOH}$. In comparison to the sensor in the absence of $\mathrm{Ir}-\mathrm{COOH}$, the LOD further decreased from 100 to $10 \mathrm{ag} / \mathrm{mL}$. 

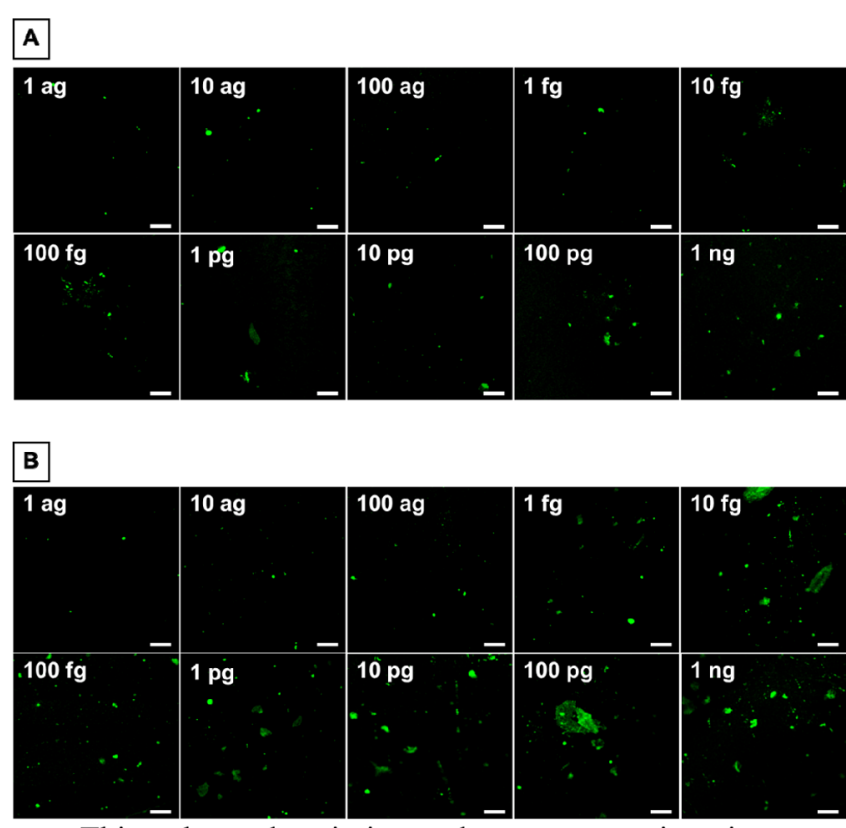

Figure 2. Confocal images of an electrode modified with 16-MHDA and the in-house-generated mAb20B3 (A) and a commercially available Hytest mAb228 primary antibody (B), following exposure to the cTnI target $(1 \mathrm{ag} / \mathrm{mL}$ to $1 \mathrm{ng} / \mathrm{mL})$ and the $\operatorname{Ir}(\mathrm{III})$-labeled commercial secondary antibody (mAb19C7). Luminescence images were recorded live on a Zeiss LSM510 Meta confocal microscope using a $40 \times$ oil immersion objective lens (NA 1.4) and a $488 \mathrm{~nm}$ argon ion laser applied for iridium-labeled antibody imaging. Scale bar $20 \mu \mathrm{m}$.

The LOD of this sensor has proven to be lower than that achieved by a commercially available electrochemical sensor from Abbott, i-STAT, that can detect cTnI at levels $80 \mathrm{ng}$ $\mathrm{mL}^{-1}{ }^{48}$ Once more, the sensitivity of the assay using the custom-synthesized mAb20B3 primary antibody was compared to a commercial antibody (Hytest 228) with a similar epitope, after the incubation of cTnI and Ir(III)-labeled secondary antibody. Significantly, as shown in Figure 1B $\mathbf{\square}$, the sensitivity of the assay using commercial antibodies was approximately $34 \%$ lower with an LOD of $1 \mathrm{fg} / \mathrm{mL}$.

In conclusion, these data suggest that $\mathrm{mAb} 20 \mathrm{~B} 3$ utilized as a primary antibody demonstrates extremely high affinity for cTnI. The capture efficiency of the in-house-generated mAbs has enhanced the overall sensitivity of the impedimetric response because of a greater quantity of cTnI immobilized on the electrode surface for each given target concentration.

Confocal Characteristics of the cTnl Immunosensor. To evaluate the troponin (cTnI) surface coverage and labeling efficiency of $\mathrm{Ir}-\mathrm{COOH}-\mathrm{mAb}$, confocal luminescence microscopy was employed. The extent of nonspecific binding of antibodies to 16-MHDA was investigated, that is, when the capture antibody and cTnI target are absent. The 16-MHDA layer was exposed to $\mathrm{Ir}-\mathrm{COOH}-\mathrm{mAb}(100 \mu \mathrm{g} / \mathrm{mL}$ stock concentration) for $1 \mathrm{~h}$ at $37^{\circ} \mathrm{C}$. For all three antibodies, negligible fluorescence is observed following exposure to the labeled antibody, suggesting that nonspecific binding is not a significant issue for these capture surfaces (Supporting Information, Figure S7).

Figure 2 shows the representative confocal luminescence images of the in-house-generated mAb-20B3 (A) and commercially available mAb228 (B)-modified electrodes after exposure to suspensions of $\mathrm{cTnI}$ at concentrations ranging from $1 \mathrm{ag} / \mathrm{mL}$ to $1 \mathrm{ng} / \mathrm{mL}$, followed by exposure to the Irlabeled secondary antibody mAb19C7 for $1 \mathrm{~h}$ at $37{ }^{\circ} \mathrm{C}$. For both antibodies, the emission intensity increases with increasing troponin concentration for both the $20 \mathrm{~B} 3 \mathrm{mAb}$ and $228 \mathrm{mAb}$-functionalized electrode surface. Significantly, the fluorescence intensity for $1 \mathrm{ng}$ cTnI with the Ir-mAb19C7 antibody was $30 \%$ higher for mAb20B3 capture antibody compared to the Hytest mAb228 one. This enhanced emission at low concentrations is potentially useful for the early detection of cTnI.

mAb20B3 as the Secondary (Detection) Antibody. Impedance Measurements for the Modification of Gold Electrodes with mAb-19C7 as the Capturing Antibody. Commercially available cTnI assays are highly cardiac specific and typically target the N-terminal region (amino acids $41-$ 49). In accordance with commercial tests, the performance of the assay was carried out using Hytest mAb19C7 (epitope region 41-49) as the primary antibody. Non-faradaic electrochemical impedance study measurements were carried out to characterize the 16-MHDA SAM-conjugated mAb19C7 gold electrode. As previously demonstrated, a clear semicircle was observed for the bare gold electrode with an average $R_{\mathrm{ct}}$ value of $248 \pm 116 \Omega$ (Supporting Information, Figure S8) for the average of 30 independent electrodes. The $R_{\text {ct }}$ value further increased to $2064 \pm 64 \Omega$ for the 16-MHDA SAM-modified electrode. The covalent attachment of Hytest mAb19C7 (100 $\mu \mathrm{g} / \mathrm{mL}$ ) on the electrode surface introduces a barrier to the interfacial charge transfer, which is clearly indicated by the significant increase of $R_{\mathrm{ct}}$ of the electrode to the value $5670 \pm$ $118 \Omega$. Hytest $19 \mathrm{C} 7$ is an immunoglobulin G2 (IgG2b) antibody and has unique biological properties compared to $\mathrm{mAb} 20 \mathrm{~B} 3 / \mathrm{mAb} 228$ (IgG1). IgG1 is thought to have a more open and flexible (leaky) conformation than the more compact and rigid IgG2b as it only has two disulfide bonds in its hinge region (four in IgG2b). ${ }^{49}$ The highly packed nature of the parent antibodies, Hytest 19C7, was largely reflected in the Nyquist plot, suggesting that structural differences in the $\mathrm{CH} 1$ domain (nonleaky) are responsible for the $41 \%$ increased resistance observed $\left(R_{\mathrm{ct}}=5670 \pm 118 \Omega\right)$ when compared to mAb20B3 $(4019 \pm 89 \Omega){ }^{50}$

Impedance Characteristics of the cTnl Immunosensor with $N$ Terminal Targeted Primary Antibody. Impedance studies focusing on the detection and quantification of cTnI protein-19C7 were performed on planar gold disk electrodes. The calibration profiles of complex plane Nyquist plot $\left(-Z^{\prime \prime}\right.$ vs $Z^{\prime}$ where $Z^{\prime \prime}$ is the imaginary impedance and $Z^{\prime}$ the real impedance) and admittance plot $\left(-Y^{\prime \prime}\right.$ vs $Y^{\prime}$ where $Y^{\prime \prime}$ represents the imaginary part of admittance and $Y^{\prime}$ the real part) are given in Figure $3 A, B$, respectively. Concentrationdependent impedance measurements are calculated based on the theory of charge generation and transportation at the electrode interface. ${ }^{20}$ This is due to the fact that proteins in solution act as polyelectrolytes and hence its electrical charge will be affected upon binding. ${ }^{51}$ It is apparent that the $Z^{\prime}$ component and the $Z^{\prime \prime}$ component of impedance, Figure 3A, both increase with increasing frequency from the baseline/ antibody trace. This figure shows that antibody and cTnI binding (both proteins) promoted a substantial increase in the barrier to charge transfer at the MHDA/gold surface. In the admittance plane (Figure 3B), the frequency decreases from right to left as the concentration of $\mathrm{cTnI}$ increases. The semicircle is due to the double-layer capacitance and solution 

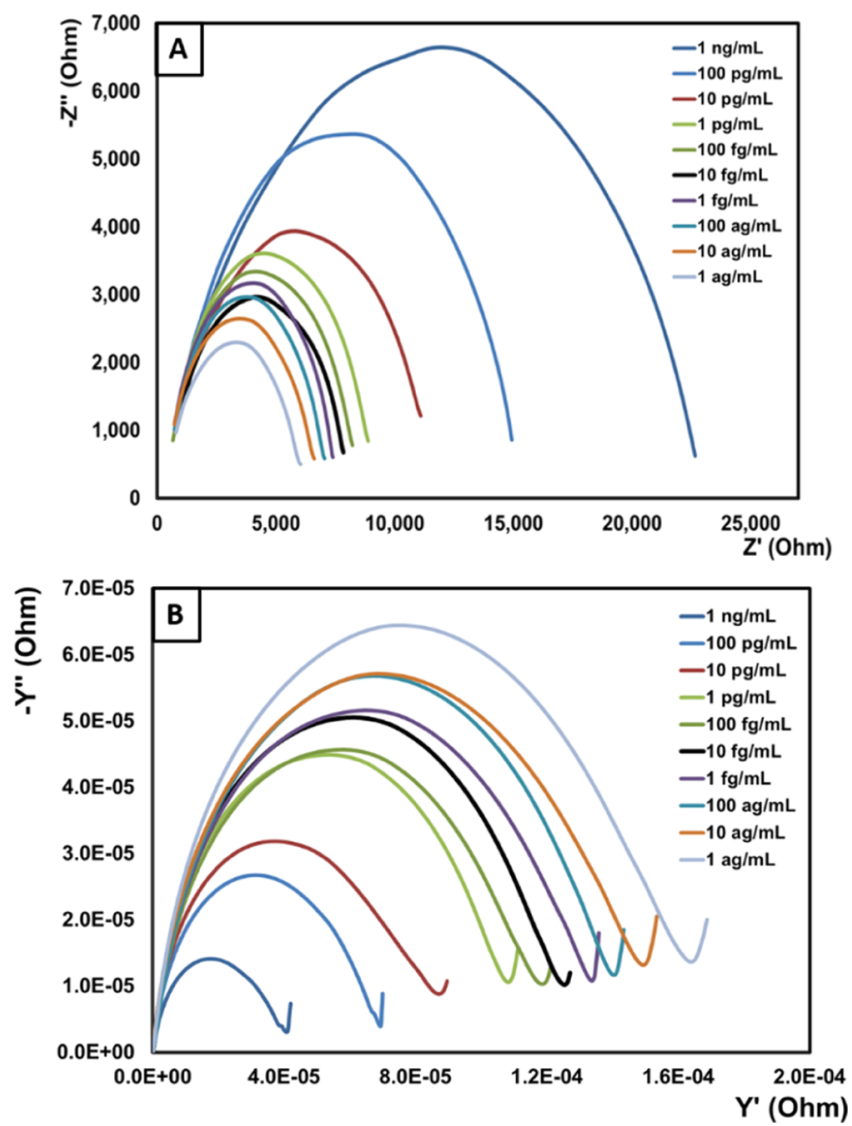

Figure 3. Nyquist (A) and admittance (B) plots of anti-cTnI (mAb19C7, epitope region 41-49) bound to modified gold electrodes with the concentration of cTnI systematically varied from $1 \mathrm{ag} / \mathrm{mL}$ to $1 \mathrm{ng} / \mathrm{mL}(N=3)$. The EIS spectra were recorded in the presence of $1 \mathrm{mM}$ DPBS using an amplitude of $25 \mathrm{mV}$ and the dc potential set to the OCP. The frequency range was between 0.01 and $100000 \mathrm{~Hz}$

resistance of the antibody-cTnI hybridization. In addition, to calculate the calibration equation, the plot of $R_{\mathrm{ct}}$ vs the concentration of cTnI was illustrated (Figure 4A, $\diamond$ ). Two linear segments were observed; one in the concentration range of $1 \mathrm{ag} / \mathrm{mL}$ to $100 \mathrm{fg} / \mathrm{mL}$ and the other in $1 \mathrm{pg} / \mathrm{mL}$ to $1 \mathrm{ng} /$ $\mathrm{mL}, y=527.6 x+16016$ and $y=4543.6 x+63838$, respectively. Each data point attained is an average value of three replicate measurements. The variances observed for the calculated slopes for the calibration segments were due to different activities of the sensor surface in low- and high-concentration solutions of the analyte. ${ }^{52}$ For the higher concentrations (between $1 \mathrm{pg} / \mathrm{mL}$ and $1 \mathrm{ng} / \mathrm{mL}$ ), the increasing $R_{\mathrm{ct}}$ indicates a rapid increase of troponin immobilized onto the modified sensor surface and therefore hindered charge transfer. Similar to the label-free sensor modified with mAb20B3_cTnI (Figure 1A, O), the LOD of mAb19C7_cTnI was determined to be $100 \mathrm{ag} / \mathrm{mL}$, which was based on the standard deviation of the blank noise (95\% confidence level, $n=3$ ).

Impedance Characteristics of cTnI Using Ir(III)-Labeled $m A b 20 B 3$ Secondary Antibody. Using the iridium-labeled secondary antibody results in a resistance that (Figure $4 \mathrm{~A}, \boldsymbol{O}$ ) is approximately 6 times larger than that found in the label-free assay. In the presence of $\mathrm{Ir}-\mathrm{mAb} 20 \mathrm{~B} 3$, a linear range from 1 $\mathrm{ng} / \mathrm{mL}$ to $1 \mathrm{ag} / \mathrm{mL}$ was obtained for cTnI detection, with a detection limit of 10 ag ( $3 \sigma /$ slope). The best fit linear

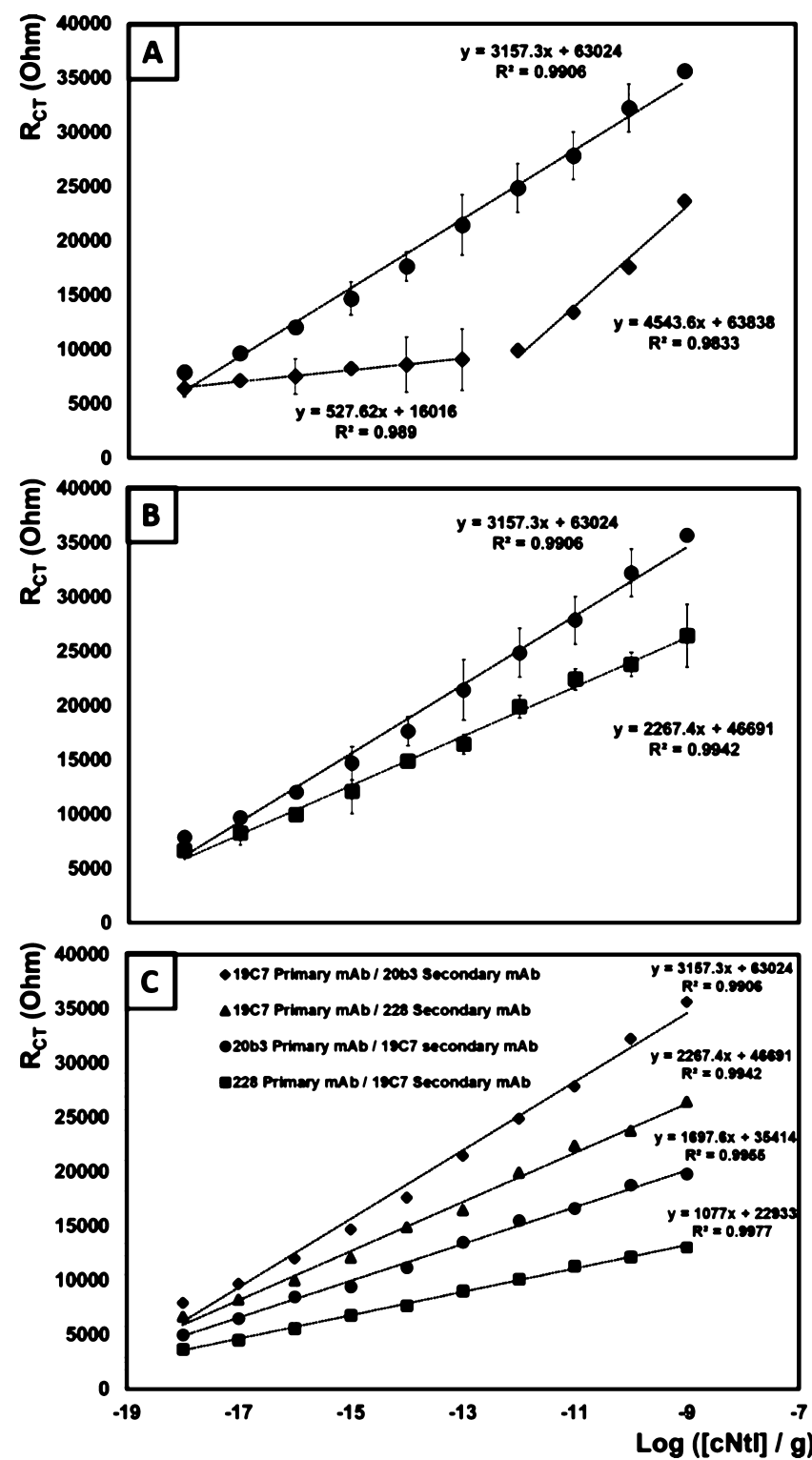

Figure 4. (A) Linear regression of anti-cNtI (Hytest 19C7, epitope region 41-49) following exposure to increasing $\mathrm{cTnI}$ target $(\diamond, 1 \mathrm{ag} /$ $\mathrm{mL}$ to $1 \mathrm{ng} / \mathrm{mL}$ ) and after immobilization of the $\operatorname{Ir}(\mathrm{III})$-labeled inhouse mAb 20B3 (-) and (B) commercially available mAb 228 (ם) secondary antibody. (C) Linear regression plots of four sandwich immunoassays with in-house-generated and commercially available antibodies, following exposure to the cTnI target $(1 \mathrm{ag} / \mathrm{mL}$ to $1 \mathrm{ng} /$ $\mathrm{mL}$ ) and $\operatorname{Ir}(\mathrm{III})$-labeled secondary antibody. In all cases, the supporting electrolyte is $1 \mathrm{mM}$ DPBS and EIS was recorded between 0.01 and $100000 \mathrm{~Hz}$ using an ac amplitude of $25 \mathrm{mV}$ and the dc potential set to the OCP $(N=3)$.

regression equation was $y=3157.3 \pm 185.7 x+63024 \pm$ $3724.8\left(R^{2}=0.9906\right)$ and RSD was in between 1 and $13 \%(n=$ 3) for all cTnI concentration levels. LOD is less than $0.1 \mathrm{ng} /$ $\mathrm{mL}$, which could provide a useful insight into the onset of AMI. The performance of this sensor was compared with the one having $\mathrm{Ir}-\mathrm{COOH}-\mathrm{mAb} 228$ as secondary antibody. Similar to the in-house-generated antibody, the linear range spans from 1 ag to $1 \mathrm{ng} / \mathrm{mL}$ with an LOD of $10 \mathrm{ag} / \mathrm{mL}$ (Figure $4 \mathrm{~B}, \square)$. However, there was a $28 \%$ decrease in sensitivity when compared to the $\mathrm{Ir}-\mathrm{COOH}-\mathrm{mAb} 20 \mathrm{~B} 3$ sandwich assay (Figure $4 \mathrm{~B}, \mathrm{O}$ ), indicating that less $\mathrm{Ag}-\mathrm{Ab}$ interactions took 
place and the affinity of mAb228 is less for cTnI than our inhouse-generated mAb-20B3. Similarly, confocal microscopy was used to better indication of the density and distribution of $\mathrm{Ir}-\mathrm{COOH}$ in the sample for different analyte concentrations. Figures $S 9$ and S10 in the Supporting Information show the confocal images for the mAb19C7 cTnI $(1 \mathrm{ag} / \mathrm{mL}$ to $1 \mathrm{ng} /$ $\mathrm{mL}$ )-modified electrodes following labeling with $\mathrm{Ir}-\mathrm{mAb} 20 \mathrm{~B} 3$ (Supporting Information S9) and Ir-mAb228 (Supporting Information S10) for $1 \mathrm{~h}$ at $37^{\circ} \mathrm{C}$. For both studies, it can be clearly seen that a very large percentage of active binding sites is occupied by iridium and the images show the cumulative fluorescent intensity of $\mathrm{Ir}-\mathrm{COOH}$ after the incubation of increasing concentrations of captured troponin for both the $\mathrm{mAb} 20 \mathrm{~B} 3$ - and $\mathrm{mAb} 228$-functionalized electrode surface.

In the present study, we have compared two groups of mAbs specific to human cTnI. The novel mAb, 20B3, was benchmarked against leading commercial antibodies and in a two-site immunoassay for cTnI. A comparison of all four immunoassays carried out is shown in Figure 4C with alternating primary and secondary $\mathrm{mAb}$ combinations (Supporting Information, Scheme S1). It can be clearly seen that the combination of $\mathrm{N}$-terminal specific antibodies for the capturing of $\mathrm{cTnI}$ with our novel mAb labeled with $\operatorname{Ir}$ (III) gave a very low $L O D$ of $10 \mathrm{ag}$. The improved diagnostic sensitivity of this assay could significantly affect the number of AMI diagnoses and thereby crucial for decision making about appropriate therapy.

\section{CONCLUSIONS}

To conclude, this study highlights a proof-of-concept example for a novel, robust, and extremely sensitive electrochemical immunoassay for the detection of troponin I, which is a biomarker for myocardial infarction. We have combined $\mathrm{mAb}$ technology with EIS to produce a high-performance assay for the determination of the cardiac biomarker. Significantly, an Ir(III) complex was employed as a label for the detection antibody, producing a sensor capable of giving an enhanced impedance response that can be readily detected. LOD resulted $10 \mathrm{ag} / \mathrm{mL}$, which to our knowledge is the first reported bioassay capable of detecting cTnI at these detection levels. Specifically, we tested an in-house antibody (mAb20B3) against a similar commercially available antibody with the same epitope target region ( $\mathrm{mAb} 228$ ), observing its superiority in selectivity and sensitivity in capturing and detecting. This work opens the possibility for a broader application of $\mathrm{mAb}$ engineering across other biologically relevant biomarkers, and we are currently pursuing this opportunity. By combining $\mathrm{mAb}$ engineering with low background detection techniques such as EIS, there exists significant potential for the development of a new generation of rapid, sensitive, and selective biosensors as well as substantial scope for the improvement of current systems, all with a common aim of improving point-of-care health monitoring. Future work will focus on measurements in whole blood/serum. Given the sensitivity of the current assay to the LOD of cTnI, there is reason to be optimistic about the sensor's performance in these clinical samples.

\section{EXPERIMENTAL SECTION}

Materials. MAb228 (epitope region 26-35) and MAb19c7 (epitope region 41-49) were purchased from HyTest Company. The novel antibody, mAb20B3 (epitope 24-39, NYRAYATEPHAKKKSKI), was custom-generated "in house".
1-Ethyl-3-[3-dimethylaminopropyl] carbodiimide hydrochloride (EDC), sulfo- $N$-hydroxysuccinimide (NHS), DPBS, 16MHDA, dimethylsulfoxide (DMSO), N,N-dimethylformamide, tetrabutylammonium tetrafluoroborate, tri- $n$-propylamine, and Triton X-100 were purchased from Sigma-Aldrich and used as received. Ir(6-phenylphenanthridine $)_{2}$ 2-(carboxyethylphenyl)pyridine-2-carboxylic acid ( $\mathrm{Ir}-\mathrm{COOH}$ ) was synthesized, as reported elsewhere. ${ }^{53}$

Instrumentation. EIS and voltammetry were performed using a $\mathrm{CH}$ Instruments, model 760E, electrochemical workstation. A traditional three-electrode electrochemical cell was set up $\left(22 \pm 2{ }^{\circ} \mathrm{C}\right)$. A $2 \mathrm{~mm}$ diameter planar gold disk modified with the capture antibody was employed as the working electrode. The counter electrode was a large area coiled with a platinum wire and silver/silver chloride (Ag/ $\mathrm{AgCl}$ in $3 \mathrm{M} \mathrm{KCl}$ ) acted as a reference. EIS measurements were performed inside a Faraday cage in $1 \mathrm{mM}$ DPBS $(\mathrm{pH}=$ 7.4) at the OCP in the frequency range of $0.01-100000 \mathrm{~Hz}$, with a $25 \mathrm{mV}$ ac amplitude. Time-resolved emission lifetime and anisotropy measurements were executed on a PicoQuant FluoTime 100 time-correlated single-photon counting system $\left(\lambda_{\mathrm{ex}}=458 \mathrm{~nm}\right)$ using a Thurlby Thandar Instruments TGP110 $10 \mathrm{MHz}$ pulse generator. Luminescence images were recorded on a Zeiss LSM510 Meta confocal microscope using a $40 \times$ oil immersion objective lens (NA 1.4) and a $488 \mathrm{~nm}$ argon ion laser applied for iridium-labeled antibody imaging.

\section{METHODS}

Photophysical Characterization of Ir-mAbs. Because of oxygen sensitivity, polarized emissions, and long emission decays of cyclometalated $\operatorname{Ir}(\mathrm{III})$ complexes, luminescence lifetime and time-resolved luminescence anisotropy were utilized to confirm antibody-Ir conjugation. In particular, oxygen sensitivity is important as small changes in the $\mathrm{O}_{2}$ accessibility of the metal center can cause significant changes in luminescent lifetime, which can be a useful confirmation of biomolecule conjugation, in the case of this study, Ir-antibody conjugation. In all cases, an increase in luminescent lifetime was observed (Supporting Information, Table S1 and Figure $\mathrm{S} 2$ ). Interestingly, the lifetime for mAb20B3-Ir conjugate increased approximately 2 -fold compared to $\mathrm{Ir}-\mathrm{COOH}$ alone, which is likely due to conformational arrangements in which the complex is protected more from water and oxygen quenching.

Anisotropy utilizes rotational time $\theta$ measurements associated with the emission transition moment that lies along the fluorophore structure. ${ }^{54}$ The rotational time depends on the viscosity of the solvent and on the size of the fluorophore. ${ }^{55}$ The bigger the fluorophore is, for example, fluorophore bound to a protein, the longer the rotational time necessary to achieve a depolarized emission. From the data recorded (Supporting Information, Table S1 and Figure S3), the free complex did not present any anisotropy as predicted, whereas the Ir-antibody conjugates presented rotational times ranging from 480 to $760 \mathrm{~ns}$. The fundamental anisotropy, r0, ranged from 0.4 (parallel transition dipoles) to -0.2 (perpendicular dipoles) and from this value, the angle $\beta$ between the absorption and emission transition moment was calculated using eq 1

$$
r_{0}=\frac{2}{5} \frac{3 \cos ^{2} \beta-1}{2}
$$


$\beta$ Values in PBS solution ranged from 37 to $40^{\circ}$ suggesting similar dimensions following conjugation for all conjugates. Overall, luminescence lifetime and anisotropy measurements demonstrated successful Ir-antibody conjugation in all cases.

Expression and Purification of Anti-cTnl mAb20B3. Purification of mAbs. Hybridoma cells which express mAb20B3 (against cTnI epitope 24-39) were produced by previous study. ${ }^{56}$ Culture media from tissue culture flasks derived from actively growing hybridomas were centrifuged at $125 \mathrm{~g}$ for $5 \mathrm{~min}$. The supernatant was then concentrated from approximately 500-5 mL using an Amicon stir cell system (GE Healthcare) with an ultrafiltration membrane $(100 \mathrm{kDa}$ molecular weight "cut-off").

Protein G Purification of mAbs. Protein G $(2 \mathrm{~mL})$ was added to a $20 \mathrm{~mL}$ column (VWR). The column was then rinsed twice with $5 \mathrm{~mL}$ of PBS and a A cap was placed on the column base. The IgG-containing sample was added to the resin and gently mixed for $1 \mathrm{~h}$ on a roller at $4{ }^{\circ} \mathrm{C}$ before addition to the column. The flow-through was reapplied to the column. The whole process was then repeated three times. Afterward, the column was then additionally washed twice with $10 \mathrm{~mL}$ of $1 \times$ PBS ( $\mathrm{pH} \mathrm{7.5)}$ ). The antibody was eluted with 10 $\mathrm{mL}$ of $100 \mathrm{mM}$ glycine- $\mathrm{HCl}$ buffer $(\mathrm{pH} 2.5)$. The eluted fractions were analyzed by determining the absorbances at 280 $\mathrm{nm}$. The fractions of the collected eluted antibodies were then combined, concentrated, and buffer exchanged three times against filtered (using $0.2 \mu \mathrm{L}$ filter) $5 \mathrm{~mL}$ of PBS ( $\mathrm{pH} 7.5$ ) using 10000 MWCO Vivaspin columns (Sartorius, \#VS0601) by centrifuging at $3220 \mathrm{~g}$ at $4{ }^{\circ} \mathrm{C}$. Sodium dodecyl sulfatepolyacrylamide gel electrophoresis (SDS-PAGE) and western blotting (WB) were then performed for the analysis of expression and purification of $20 \mathrm{~B} 3 \mathrm{mAb}$ (Supporting Information, Figure S1). Protein concentration was determined by the bicinchoninic acid assay assay. The purified IgG was divided into $100 \mu \mathrm{L}$ aliquots and stored at $-20{ }^{\circ} \mathrm{C}$.

Figure S1 shows the SDS-PAGE and WB probed with goat anti-mouse-Fc-specific antibody, followed by horseradish peroxidase-labeled rabbit anti-goat antibody. MW: protein ladder, E2: 1:80 dilution of 20B3 mAb elution, E1: 1:20 dilution of $20 \mathrm{~B} 3 \mathrm{mAb}$ elution, W2: column wash $2, \mathrm{~W} 1$ : column wash 1, F-T: "flow-through".

Labeling of mAbs with $\operatorname{Ir}(I I I)$ Complexes. The mAbs were labeled with the $\mathrm{Ir}-\mathrm{COOH}$ complex by first activating the complex dissolved in DMSO $(0.03 \mathrm{M})$ with NHS and EDC (ration 4:1) at room temperature for $20 \mathrm{~min}$. Following this, the activated complex $(10 \mu \mathrm{L})$ was added directly to an Eppendorf tube containing $1 \mathrm{~mL}$ of DPBS solution $(\mathrm{pH}=7.4)$ of the antibody $(100 \mu \mathrm{g} / \mathrm{mL})$ and allowed to slowly stir at room temperature for $4 \mathrm{~h}$. After that, the reaction mixture was purified by different cycles of centrifugation using an ultracentrifugal tube with a cutoff of $30 \mathrm{~K}$.

Fabrication of Immunosensor. Scheme 1 illustrates the troponin I (cTnI) immunosensor. Initially, an SAM of MHDA was formed by immersing a gold electrode $(\mathrm{Au})$ for $24 \mathrm{~h}$ in an ethanol solution containing $1 \mathrm{mM} 16$ MHDA. After the SAM formation, the $\mathrm{Au} / \mathrm{MHDA}$ electrode was treated in a mixture of $5 \mathrm{mM}$ EDC, $15 \mathrm{mM}$ NHS, and DPBS solution for $20 \mathrm{~min}$ at room temperature to activate the carboxylic acid groups of MHDA. The custom capture mAb, mAb20B3 (epitope 2439 ), was subsequently covalently immobilized on the $\mathrm{Au} /$ MHA electrode by incubating the modified electrode in a 0.1 M DPBS solution ( $\mathrm{pH} 7.4$ ) containing $100 \mu \mathrm{g} / \mathrm{mL}$ stock concentration for approximately 1 hour at $37^{\circ} \mathrm{C}$. After coating with the capture $\mathrm{mAb}$, the $\mathrm{Au} / \mathrm{MHDA} / \mathrm{mAb}$ electrodes were incubated in various concentrations of troponin in the range of $1 \mathrm{ag} / \mathrm{mL}$ to $1 \mathrm{ng} / \mathrm{mL}$ for an approximately $1 \mathrm{~h}$ at $37{ }^{\circ} \mathrm{C}$. A commercial capture $\mathrm{mAb}$ with similar epitope regions (Hytest $\mathrm{mAb} 228$, epitope region 26-35) to $\mathrm{mAb} 20 \mathrm{~B} 3$ was carried out in parallel to compare the capture efficiency of the antibody. After incubation with troponin I, the functionalized electrodes were immersed in a DPBS solution containing the soluble labeled $\mathrm{Ir}-\mathrm{mAb} 19 \mathrm{c} 7(100 \mu \mathrm{g} / \mathrm{mL}$ stock concentration) for $1 \mathrm{~h}$ at $37{ }^{\circ} \mathrm{C}$ and again washed, prior to electrochemical analysis.

Cross-Reactivity of mAbs. In order to determine whether the system has a high affinity to the specific cTns or is a generic capture platform, peptide-specificity analysis was carried out on Biacore 4000. Our group has previously carried out epitopespecificity studies ${ }^{56}$ and eliminated issues with reactivity against the other cTnI synthetic peptides and linker chemistries. Epitope region specificity was confirmed by mapping experiments using SPR, and discounting issues with reactivity against the other cTnI synthetic peptides and linker chemistries and positive mAbs were found to exclusively react with the synthetic peptide.

\section{ASSOCIATED CONTENT}

\section{Supporting Information}

The Supporting Information is available free of charge on the ACS Publications website at DOI: 10.1021/acsomega.8b01758.

SDS-PAGE and WB analysis of the purification of $\mathrm{mAb}$, Nyquist plots of various immunoassay optimization, confocal images of control tests as well as $1 \mathrm{ag} / \mathrm{mL}$ to 1 $\mathrm{ng} / \mathrm{mL} \mathrm{cTnI}$ immunoassays with alternative primary and secondary $\mathrm{mAbs}$, and lifetime and anisotropy rotational time of $\mathrm{Ir}-\mathrm{COOH}$ and conjugates (PDF)

\section{AUTHOR INFORMATION}

\section{Corresponding Authors}

*E-mail: Elainespain@dcu.ie (E.S.).

*E-mail: RobertForster@dcu.ie (R.J.F.).

ORCID

Elaine Spain: 0000-0001-9086-7713

Serena Carrara: 0000-0001-8921-7094

Luisa De Cola: 0000-0002-2152-6517

Robert J. Forster: 0000-0001-5079-3123

\section{Author Contributions}

This manuscript was written through contributions from all authors. All authors have given approval to the final version of the manuscript. E.S. and K.A. designed the experiments. All EIS experiments were carried out by E.S., and S.C. synthesized the $\mathrm{Ir}-\mathrm{COOH}$ conjugates and carried out the photophysical characterization, under the guidance of L.D.C., R.J.F., and K.A. Confocal microscopy was carried out by K.A., H.M. produced the mAbs under the supervision of R.K. and E.S, and S.C. wrote the manuscript under the guidance of R.J.F. All authors read and gave valuable suggestions on the manuscript.

\section{Notes}

The authors declare no competing financial interest.

\section{ACKNOWLEDGMENTS}

The authors are thankful for the financial support from Enterprise Ireland (EI) for SepTec SUSCEPT: antimicrobial susceptibility testing within 2 hour projects under the number 
CF-2016-0552-P (E.S. and R.J.F.) and for RECANT project under the number CF/2015/0105 (H.M. and R.K.). The project was also supported by Irish Research Council under the award GOIPD/2016/627 (K.A.). Supporting research was also from the University of Strasbourg under Grant AXA Research Funds (S.C. and L.D.C.).

\section{REFERENCES}

(1) Murray, C. J. L.; Lopez, A. D. Alternative projections of mortality and disability by cause 1990-2020: Global Burden of Disease Study. Lancet 1997, 349, 1498-1504.

(2) Roth, R. A.; Johnson, C.; Abajobir, A.; et al. Global, Regional, and National Burden of Cardiovascular Diseases for 10 Causes, 1990 to 2015. J. Am. Coll. Cardiol. 2017, 70, 1-25.

(3) Bakirhan, N. K.; Ozcelikay, G.; Ozkan, S. A. Recent progress on the sensitive detection of cardiovascular disease markers by electrochemical-based biosensors. J. Pharm. Biomed. Anal. 2018, 159, 406-424.

(4) Morrow, D. A.; Cannon, C. P.; Jesse, R. L.; Newby, L. K.; Ravkilde, J.; Storrow, A. B.; Wu, A. H. B.; Christenson, R. H. National Academy of Clinical Biochemistry Laboratory Medicine Practice Guidelines: Clinical characteristics and utilization of biochemical markers in acute coronary syndromes. Circulation 2007, 115, e356e375.

(5) Friess, U.; Stark, M. Cardiac markers: a clear cause for point-ofcare testing. Anal. Bioanal. Chem. 2009, 393, 1453-1462.

(6) Horak, J.; Dincer, C.; Qelibari, E.; Bakirci, H.; Urban, G. Polymer-Modified Microfluidic Immunochip for Enhanced Electrochemical Detection of Troponin I. Sens. Actuators, B 2015, 209, 478485.

(7) Mahajan, V. S.; Jarolim, P. How to interpret elevated cardiac troponin levels. Circulation 2011, 124, 2350-2354.

(8) Apple, F. S.; Pearce, L. A.; Smith, S. W.; Kaczmarek, J. M.; Murakami, M. M. Role of monitoring changes in sensitive cardiac troponin I assay results for early diagnosis of myocardial infarction and prediction of risk of adverse events. Clin. Chem. 2009, 55, 930937.

(9) Cho, I.-H.; Paek, E.-H.; Kim, Y.-K.; Kim, J.-H.; Paek, S.-H. Chemiluminometric enzyme-linked immunosorbent assays (ELISA)on-a-chip biosensor based on cross-flow chromatography. Anal. Chim. Acta 2009, 632, 247-255.

(10) Dempsey, E.; Rathod, D. Disposable printed lateral flow electrochemical immunosensors for human cardiac troponin T. IEEE Sensor. J. 2018, 18, 1828-1834.

(11) Dittmer, W. U.; Evers, T. H.; Hardeman, W. M.; Huijnen, W.; Kamps, R.; de Kievit, P.; Neijzen, J. H. M.; Nieuwenhuis, J. H.; Sijbers, M. J. J.; Dekkers, D. W. C.; Hefti, M. H.; Martens, M. F. W. C. Rapid, high sensitivity, point-of-care test for cardiac troponin based on optomagnetic biosensor. Clin. Chim. Acta 2010, 411, 868-873.

(12) Kim, K.; Park, C.; Kwon, D.; Kim, D.; Meyyappan, M.; Jeon, S.; Lee, J.-S. Silicon nanowire biosensors for detection of cardiac troponin I (cTnI) with high sensitivity. Biosens. Bioelectron. 2016, 77, 695-701.

(13) Kar, P.; Pandey, A.; Greer, J. J.; Shankar, K. Ultrahigh sensitivity assays for human cardiac troponin I using $\mathrm{TiO} 2$ nanotube arrays. Lab Chip 2012, 12, 821-828.

(14) Zhou, Y.; Zhuo, Y.; Liao, N.; Chai, Y.; Yuan, R. Ultrasensitive electrochemiluminescent detection of cardiac troponin I based on a self-enhanced $\mathrm{Ru}(\mathrm{II})$ complex. Talanta 2014, 129, 219-226.

(15) Qi, H.; Qiu, X.; Xie, D.; Ling, C.; Gao, Q.; Zhang, C. Ultrasensitive Electrogenerated Chemiluminescence Peptide-Based Method for the Determination of Cardiac Troponin I Incorporating Amplification of Signal Reagent-Encapsulated Liposomes. Anal. Chem. 2013, 85, 3886-3894.

(16) Shen, W.; Tian, D.; Cui, H.; Yang, D.; Bian, Z. Nanoparticlebased electrochemiluminescence immunosensor with enhanced sensitivity for cardiac troponin I using $\mathrm{N}$-(aminobutyl)-N-(ethyl- isoluminol)-functionalized gold nanoparticles as labels. Biosens. Bioelectron. 2011, 27, 18-24.

(17) Li, F.; Yu, Y.; Cui, H.; Yang, D.; Bian, Z. Label-free electrochemiluminescence immunosensor for cardiac troponin I using luminol functionalized gold nanoparticles as a sensing platform. Analyst 2013, 138, 1844-1850.

(18) Suni, I. I. Impedance methods for electrochemical sensors using nanomaterials. Trends Anal. Chem. 2008, 27, 604-611.

(19) Katz, E.; Willner, I. Probing Biomolecular Interactions at Conductive and Semiconductive Surfaces by Impedance Spectroscopy: Routes to Impedimetric Immunosensors, DNA Sensors and Enzyme Biosensors. Electroanalysis 2003, 15, 913-947.

(20) Spain, E.; Gilgunn, S.; Sharma, S.; Adamson, K.; Carthy, E.; Kennedy, R. O.; Forster, R. J. Detection of prostate specific antigen based on electrocatalytic platinum nanoparticles conjugated to a recombinant SCFV antibody. Biosens. Bioelectron. 2016, 77, 759-766.

(21) Elgqvist, J. Nanoparticles as Theranostic Vehicles in Experimental and Clinical Applications-Focus on Prostate and Breast Cancer. Int. J. Mol. Sci. 2017, 18, 1102.

(22) Nwankire, C. E.; Venkatanarayanan, A.; Glennon, T.; Keyes, T. E.; Forster, R. J.; Ducrée, J. Label-free impedance detection of cancer cells from whole blood on an integrated centrifugal microfluidic platform. Biosens. Bioelectron. 2015, 68, 382-389.

(23) Foubert, A.; Beloglazova, N. A.; Hedström, M.; De Saeger, S. Antibody immobilization strategy for the development of a capacitive immunosensor detecting zearalenone. Talanta 2019, 191, 202-220.

(24) Shoute, L. C. T.; Anwar, A.; MacKay, S.; Abdelrasoul, G. N.; Lin, D.; et al. Immuno-impedimetric Biosensor for Onsite Monitoring of Ascospores and Forecasting of Sclerotinia Stem Rot of Canola. Sci. Rep. 2018, 8, 12396.

(25) Zayats, M.; Raitman, O. A.; Chegel, V. I.; Kharitonov, A. B.; Willner, I. Probing Antigen-Antibody Binding Processes by Impedance Measurements on Ion-Sensitive Field-Effect Transistor Devices and Complementary Surface Plasmon Resonance Analyses: Development of Cholera Toxin Sensors. Anal. Chem. 2002, 74, 47634773.

(26) Jarocka, U.; Sawicka, R.; Góra-Sochacka, A.; Sirko, A.; Zagórski-Ostoja, W.; Radecki, J.; Radecka, H. An Immunosensor Based on Antibody Binding Fragments Attached to Gold Nanoparticles for the Detection of Peptides Derived from Avian Influenza Hemagglutinin H5. Sensors 2014, 14, 15714-15728.

(27) Henry, O. Y. F.; Perez, J. G.; Sanchez, J. L. A.; O’Sullivan, C. K. Electrochemcial characterisation and hybridisation efficiency of coassembled monolayers of PEGylated ssDNA and mercaptohexanol on planar gold electrodes. Biosens. Bioelectron. 2010, 25, 978-983.

(28) Şimșek, C. S.; Karaboğa, M. N. S.; Sezgintürk, M. K. A new immobilization procedure for development of an electrochemical immunosensor for parathyroid hormone detection based on gold electrodes modified with 6-mercaptohexanol and silane. Talanta 2015, 144, 210-218.

(29) Chen, Z.-q.; Bian, Z.-q.; Huang, C.-h. Functional IrIII Complexes and Their Applications. Adv. Mater. 2010, 22, 1534-1539.

(30) Shiu, H.-Y.; Chong, H.-C.; Leung, Y.-C.; Zoua, T.; Che, C.-M. Phosphorescent proteins for bio-imaging and site selective bioconjugation of peptides and proteins with luminescent cyclometalated iridium (III) complexes. Chem. Commun. 2014, 50, 4375-4378.

(31) Masum, A.-A.; Hisamatsu, Y.; Yokoi, K.; Aoki, S. Luminescent Iridium Complex-Peptide Hybrids (IPHs) for Therapeutics of Cancer: Design and Synthesis of IPHs for Detection of Cancer Cells and Induction of Their Necrosis-Type Cell Death. Bioinorg. Chem. Appl. 2018, 2018, 7578965.

(32) Zhou, M.; Xia, Y. Electrochemiluminescence immunoassay based on site-specific labeling using a histidine-binding iridium(III) solvento complex. Anal. Chim. Acta 2018, 1023, 29-34.

(33) Miao, X.; Yang, C.; Leung, C.-H.; Ma, D.-L. Application of iridium(III) complex in label-free and nonenzymatic electrochemical detection of hydrogen peroxide based on a novel "on-off-on" switch platform. Sci. Rep. 2016, 6, 25774. 
(34) Fernandez-Hernandez, J. M.; Longhi, E.; Cysewski, R.; Polo, F.; Josel, H.-P.; De Cola, L. Photophysics and Electrochemiluminescence of Bright Cyclometalated $\operatorname{Ir}(\mathrm{III})$ Complexes in Aqueous Solutions. Anal. Chem. 2016, 88, 4174-4178.

(35) Akter, R.; Jeong, B.; Lee, Y.-M.; Choi, J.-S.; Rahman, M. A. Femtomolar detection of cardiac troponin I using a novel label-free and reagent-free dendrimer enhanced impedimetric immunosensor. Biosens. Bioelectron. 2017, 91, 637-643.

(36) Periyakaruppan, A.; Gandhiraman, R. P.; Meyyappan, M.; Koehne, J. E. Label-free detection of cardiac troponin-I using carbon nanofiber based nanoelectrode arrays. Anal. Chem. 2013, 85, 38583863.

(37) Singh, N.; Ali, M. A.; Rai, P.; Sharma, A.; Malhotra, B. D.; John, R. Microporous nanocomposite enabled microfluidic biochip for cardiac biomarker detection. ACS Appl. Mater. Interfaces 2017, 9, 33576-33588.

(38) Xiong, M.; Wang, X.; Kong, Y.; Han, B. Development of cardiac troponin I electrochemical impedance immunosensor. Int. J. Electrochem. Sci. 2017, 12, 4204-4214.

(39) Forster, R. J. Heterogeneous Kinetics of Metal- and LigandBased Redox Reactions within Adsorbed Monolayers. Inorg. Chem. 1996, 35, 3394-3403.

(40) Forster, R. J.; O’Kelly, J. P. pH Modulated Heterogeneous Electron Transfer across Metal/Monolayer Interfaces. J. Phys. Chem. 1996, 100, 3695-3704.

(41) Venkatanarayanan, A.; Keyes, T. E.; Forster, R. J. Label-Free Impedance Detection of Cancer Cells. Anal. Chem. 2013, 85, 22162222

(42) Akiba, U.; Anzai, J. Recent Progress in Electrochemical Biosensors for Glycoproteins. Sensors 2016, 16, 2045.

(43) Luna, D. M. N.; Avelino, K. Y. P. S.; Cordeiro, M. T.; Andrade, C. A. S.; Oliveira, M. D. L. Electrochemical immunosensor for dengue virus serotypes based on 4-mercaptobenzoic acid modified gold nanoparticles on self-assembled cysteine monolayers. Sens. Actuators, B 2015, 220, 565-572.

(44) Andris-Widhopf, J.; Rader, C.; Steinberger, P.; Fuller, R.; Barbas, C. F., III Methods for the generation of chicken monoclonal antibody fragments by phage display. J. Immunol. Methods 2000, 242, $159-181$.

(45) Teixeira, S.; Conlan, R. S.; Guy, O. J.; Sales, M. G. F. Label-free human chorionic gonadotropin detection at picogram levels using oriented antibodies bound to graphene screen-printed electrodes. $J$. Mater. Chem. B 2014, 2, 1852-1865.

(46) Santos, A.; Davis, J. J.; Bueno, P. R. Fundamentals and Applications of Impedimetric and Redox Capacitive Biosensors. J. Anal. Bioanal. Tech. 2014, S7-016. DOI: 10.4172/2155-9872.s7-016

(47) Malvano, F.; Maritato, L.; Carapella, G.; Orgiani, P.; Pilloton, R.; Di Matteo, M. D.; Albanese, D. Fabrication of $\mathrm{SrTiO}_{3}$ layer on $\mathrm{Pt}$ electrode for label-free capacitive biosensors. Biosensors 2018, 8, 26.

(48) Venge, P.; van Lippen, L.; Blaschke, S.; Christ, M.; et al. Equal clinical performance of a novel point-of-care cardiac troponin I (cTnI) assay with a commonly used high-sensitivity cTnI assay. Clin. Chim. Acta 2017, 469, 119-125.

(49) Beers, S. A.; Glennie, M. J.; White, A. L. Influence of immunoglobulin isotype on therapeutic antibody function. Blood 2016, 127, 1097-1101.

(50) Hovenden, M.; Hubbard, M. A.; AuCoin, D. P.; Thorkildson, P.; Reed, D. E.; Welch, W. H.; Lyons, C. R.; Lovchik, J. A.; Kozel, T. R. IgG subclass and heavy chain domains contribute to binding and protection by mAbs to the poly $\gamma$-D-glutamic acid capsular antigen of Bacillus anthracis. PLoS Pathog. 2013, 9, e1003306.

(51) Prasad, B.; Lal, R. A capacitive Immunosensor measurement system with a lock in amplifier and potentiostatic control by software. Meas. Sci. Technol. 1999, 10, 1097-1104.

(52) Biniaz, Z.; Mostafavi, A.; Shamspur, T.; Torkzadeh-Mahani, M.; Mohamadi, M. Electrochemical sandwich immunoassay for the prostate specific antigen using a polyclonal antibody conjugated to thionine and horseradish peroxidase. Microchim. Acta 2017, 184, 2731-2738.
(53) Lamansky, S.; Djurovich, P.; Murphy, D.; Abdel-Razzaq, F.; Kwong, R.; Tsyba, I.; Bortz, M.; Mui, B.; Bau, R.; Thompson, M. E. Synthesis and Characterization of Phosphorescent Cyclometalated Iridium Complexes. Inorg. Chem. 2001, 7, 1704-1711.

(54) Ameloot, M.; vandeVen, M.; Acuña, A. U.; Valeur, B. Fluorescence anisotropy measurements in solution: Methods and reference materials (IUPAC Technical Report). Pure Appl. Chem. 2013, 85, 589-608.

(55) Barbero, N.; Napione, L.; Quagliotto, P.; Pavan, S.; Barolo, C.; Barni, E.; Bussolino, F.; Viscardi, G. Fluorescence anisotropy analysis of protein-antibody interaction. Dyes Pigm. 2009, 83, 225-229.

(56) Conroy, P. J.; O’Kennedy, R. J.; Hearty, S. Cardiac troponin I: a case study in rational antibody design for human diagnostics. Protein Eng. Des. Sel. 2012, 25, 295-305. 